\title{
Comercialização de plantas medicinais por raizeiros, na feira livre, em São José de Piranhas, Paraíba
}

\section{Commercialization of medicinal plants by raizers, at the fair, in São José de Piranhas, state Paraíba}

\author{
Carla Heloísa Alencar de Figueiredo \\ Graduanda em Farmácia, FASP, E-mail: carlaheloisaf@gmail.com \\ Maria Carmem Batista de Alencar \\ Mestranda em Sistemas Agroindustriais, UFCG, E-mail: carmemsjp@ hotmail.com \\ Samara Raquel Souza Ribeiro \\ Mestranda em Sistemas Agroindustriais, UFCG, E-mail:samararibeiroa@gmail.com
}

\begin{abstract}
Resumo: As plantas medicinais são formas de tratamento alternativo e, para algumas pessoas a única opção para essa finalidade. Assim objetivou-se realizar uma investigação sobre a diversidade de recursos vegetais comercializados em feira livre, no município de São José de Piranhas no estado da Paraíba, uma vez que o estudo das espécies medicinais trará subsídios para a sua correta indicação e forma de uso. A coleta de informações foi realizada por meio de visitas à feira livre, a fim de estabelecer contato, e observando-se os feirantes que comercializam plantas medicinais no município. A etnobotânica nos mostra a importância dos comerciantes de plantas medicinais para informação sobre o devido uso, de modo que fazem a ligação entre produção/venda e o uso destes produtos. Foram citados pelos erveiros da feira livre de São José de Piranhas 18 espécies e 10 famílias de plantas medicinais comercializadas. A venda e utilização de plantas medicinais nas mais diversas formas e finalidades é uma prática bem difundida na cidade de São José de Piranhas-PB.
\end{abstract}

Palavras-chave: Etnobotânica; Erveiros; Remédio natural.

\begin{abstract}
Medicinal plants are alternative forms of treatment and, for some people, still the only option for such. The objective of this work was to carry out an investigation about the diversity of vegetal resources commercialized in a fair, in the municipality of São José de Piranhas in the state of Paraiba, since the study of medicinal species will provide subsidies for its correct indication and form of use. The collection of information was carried out through visits to the fair, in order to establish contact, and observing the herbs that market medicinal plants in the municipality. Ethnobotany shows us the importance of the traders of medicinal plants for information about the proper use, so that they make the connection between production / sale and the use of these products. There were 18 species and 10 families of medicinal plants marketed by them. It can be concluded that the sale and use of medicinal plants in the most diverse forms and purposes is a well-known practice in the city of São José de Piranhas-PB.
\end{abstract}

Keywords: Ethnobotany; Erveiros; Natural remedy. 


\section{INTRODUÇÃO}

As plantas medicinais são formas de tratamento alternativo, que são utilizadas desde a antiguidade, capazes de promover a cura e prevenção de diversas enfermidades. A Organização Mundial de Saúde (OMS), devido ao crescimento histórico do uso de plantas medicinais, reconheceu a fitoterapia como uma alternativa terapêutica no tratamento de doenças (PASA, 2011).

O emprego de plantas medicinais no processo de cicatrização de feridas é mencionado desde a pré-história, em que eram utilizados plantas e extratos vegetais para o cuidado humano. (PIRIZ, et al, 2015).

Os benefícios à saúde são em decorrência ao uso adequado das plantas que possuem caráter medicinal, desde a prevenção ao tratamento de diversas doenças, sendo, necessário que os usuários usem de forma racional tendo conhecimento de suas indicações, pois, mesmo se tratando de produtos de origem natural, não estão isentos de riscos, como intoxicações (PEREIRA, 2015).

O comércio e o uso de plantas medicinais são bastante conhecidos e discutidos no Brasil e no mundo. $\mathrm{O}$ mercado atende de diferentes formas o consumidor desse tipo de produto, incluindo as comercializações realizadas em empresas, em mercados e em ervanários (BRANDÃO et al., 1998).

Os comerciantes de plantas medicinais, também conhecidos como erveiros ou raizeiros são essenciais na disseminação dos conhecimentos a respeito da indicação e forma de uso destas plantas, apesar de não conhecer os aspectos científicos, apresentam domínio sobre a cultura popular, passada de geração a geração. Muitos consideram as plantas como métodos substanciais na cura e prevenção de doenças, mesmo comparado aos medicamentos alopáticos, além disso, se mostram curiosos à respeito das informações científicas acerca das plantas medicinais (SILVA, 2014).

De acordo com Sousa e Felfile (2006) a utilização das plantas medicinais deve levar em consideração o contexto social e cultural no qual estes usos estão inseridos. Com isso, tem-se uma carência muito grande de levantamentos etnobotânicos. O interesse de busca de conhecimentos sobre a biodiversidade da do bioma caatinga ainda é um desafio, de modo que os poucos estudos existentes, estão concentrados a poucas regiões. No Nordeste, especialmente no semiárido, a caatinga é a vegetação predominante, possui características especiais, o que as leva a adaptar-se melhor aos longos períodos de estiagem e clima seco. A vegetação mais expressa da caatinga são as árvores e arbustos espinhentos com folhagem decídua, se caracteriza também por vegetações principais cidades da região Nordeste, o que não gera uma grande abrangência (MELO-BATISTA, 2014)

Assim objetivou-se investigar a diversidade de recursos vegetais comercializados em feira livre, no município de São José de Piranhas-PB, uma vez que o estudo das espécies medicinais trará subsídios para a sua correta indicação e forma de uso.

\section{MATERIAIS E MÉTODOS}

A coleta de informações foi realizada por meio de visitas à feira livre, a fim de estabelecer contato, e observando-se os feirantes (erveiros) que comercializam plantas medicinais no município de São José de PiranhasPB.

A observação e entrevistas foram utilizada para coleta de informações como os dados sociais e tópicos que auxiliam no esclarecimento sobre as plantas medicinais comercializadas no município.

A feira livre da cidade de São José de Piranhas$\mathrm{PB}$, acontece às segundas-feiras no centro da cidade. Os feirantes montam "bancas", como são chamados os espaços de comercialização.

\section{RESULTADOS E DISCUSSÃO}

Na feira livre da cidade de São José de PiranhasPB conta com a participação de 5 erveiros, feirantes que comercializam de plantas medicinais, sendo $4(80 \%)$ homens, e apenas 1 mulher (20\%). Todos possuíam idade acima de 40 anos, com faixa etária prevalente de 50 a 60 anos. Quanto ao nível de escolaridade apenas 2 possuíam o ensino fundamental completo (20\%), 1 analfabeto $(20 \%)$ e 2 com ensino fundamental incompleto (40\%).

Ainda de acordo com os dados observados, $80 \%$ dos comerciantes entrevistados aprenderam a profissão por meio de familiares que trabalhavam. É muito comum a passagem de informações através da família, e além da bagagem cultural, eles relataram que procurar informações em livros e com profissionais da área. Quanto ao tempo de profissão, $100 \%$ trabalham há mais de 10 anos em feira livre.

A etnobotânica nos mostra a importância dos comerciantes de plantas medicinais para informação sobre o devido uso, de modo que fazem a ligação entre produção/venda e o uso destes produtos. Foram citados pelos erveiros da feira livre de São José de Piranhas 18 espécies e 10 famílias de plantas medicinais comercializadas, como mostra na Tabela 1

Quanto à parte utilizada para uso medicinal em $55,5 \%$ das plantas citadas, são utilizadas as folhas, seja para fazer chá ou macerado, informação que corrobora um estudo de Moreira e Travenzoli, (2009), onde 67,5\% dos entrevistados utilizavam as folhas como material para preparação dos seus fitoterápicos.

Foram citadas plantas que servem para as mais diversas enfermidades, se destacando as indicadas para problemas digestivos/intestinais $(66.7 \%)$, seguido por plantas com capacidade analgésica, ou seja, para diminuir dores $(27,8 \%)$ e plantas com atividade calmante $(22,2 \%)$. Algumas destas plantas citadas estão entre as plantas da Relação Nacional de Plantas Medicinais do Sistema Único de Saúde (RENISUS), encaixando-se como plantas de potencial terapêutico passíveis de estudos para desenvolvimento de fitoterápicos. Além da lista do RENISUS, podemos contar com a RDC 10/2010, que regulamenta as plantas cientificamente comprovadas com ação medicinal e suas respectivas indicações. 
Tabela 1. Plantas comercializadas por feirantes erveiros na feira livre no município de São José de Piranhas no estado da Paraíba.

\begin{tabular}{|c|c|c|}
\hline Família/Nome científico & Nome Popular & Parte utilizada \\
\hline \multicolumn{3}{|l|}{ ANACARDIACEA } \\
\hline SchinusterelinthifolusRaddi* & Aroeira & Folha \\
\hline \multicolumn{3}{|l|}{ APIACEA } \\
\hline Pimpinellaanisum & Erva-doce & Folha \\
\hline \multicolumn{3}{|l|}{ ASTERACEAE } \\
\hline Achyroclinesatureoides & Macela & Folha; Flor \\
\hline Baccharistrimera & Carqueja & Casca \\
\hline Helianthus аппииs & Girassol & Semente \\
\hline Matricariachamomilla & Camomila & Folha \\
\hline Tageteserecta $L$. & Cravo & Planta \\
\hline Vernoniacondensata & Boldo & Folha \\
\hline \multicolumn{3}{|l|}{ CHENOPODIACEA } \\
\hline Chenopodiumambrosioides & Mastruz & Folha \\
\hline \multicolumn{3}{|l|}{$F A B A C E A E$} \\
\hline Mimosa hostilis & Jurema preta & Casca \\
\hline \multicolumn{3}{|l|}{ LAMIACEA } \\
\hline Melissa officinalis & Erva cidreira & \\
\hline Plectranthusbarbatus Andrews & Malva & Folha \\
\hline \multicolumn{3}{|l|}{ LAURACEA } \\
\hline Cinnamomumzeylanicum & Canela & Planta \\
\hline Laurusnobilis & Louro & Folha \\
\hline \multicolumn{3}{|l|}{ POACEAE } \\
\hline Cymbopogoncitratus & Capim-limão & Folha \\
\hline \multicolumn{3}{|l|}{ RUTACEAE } \\
\hline Rutagraveolens & Arruda & Folha \\
\hline \multicolumn{3}{|l|}{ VERBENACEAE } \\
\hline Indeterminada & Alfazema & Folha \\
\hline LippiasidoidesCham. & Alecrim-pimenta & Folha \\
\hline
\end{tabular}

\section{CONCLUSÕES}

A venda e utilização de plantas medicinais nas mais diversas formas e finalidades é uma prática bem difundida na cidade de São José de Piranhas-PB.

$\mathrm{O}$ interesse pelas propriedades farmacológicas das plantas é notório, o que nos leva a refletir sobre a necessidade de uma aplicação de educação em saúde voltada aos fitoterápicos, visando melhoria na qualidade de vida dos usuários e lhes dar oportunidade de uma medicação alternativa e mais natural.

\section{REFERÊNCIAS}

BRANDÃO, M. G. L.; FREIRE, N.; VIANNA-SOARES, C. D. Vigilância de fitoterápicos em Minas Gerais. Verificação da qualidade de diferentes amostras comerciais de camomila. Cadernos de Saúde Pública, v. 14 , n. 3, p. 613-616, 1998

SOUZA, C. D; FELFILI, J. M. Uso de plantas medicinais na região de Alto Paraíso de Goiás, GO, Brasil. Acta bot. bras. 20(1): 135-142. 2006.

MELO-BATISTA, A. A; OLIVEIRA C. R. M. Plantas utilizadas como medicinais em uma comunidade do semiárido baiano: saberes tradicionais e a conservação ambiental. Enciclopédia biosfera, Centro Científico Conhecer - Goiânia, v.10, n.18; p. 2014
PASA, M. G. Saber local e medicina popular: a etnobotânica em Cuiabá, Mato Grosso, Brasil. Bol. Mus. Para. Emílio Goeldi. Cienc. Hum., Belém, v. 6, n. 1, p. 179-196, jan.- abr. 2011

PEREIRA, A.C. S; CUNHA, M. G. C. Medicina popular e saberes tradicionais sobre as propriedades medicinais da flora cerradeira, 2015.

PIRIZL, M. A; ROESELL, A; LOPES, C. V; SILVA, M. M; HECKV, R. M; BARBIERI, R. Uso popular de plantas medicinais na cicatrização de feridas: implicações para a enfermagem. Rev enferm. UERJ. DOI: http://dx.doi.org/10.12957/reuerj.2015.5624. set/out; 23(5):674-9. Rio de Janeiro, 2015.

SILVA, P. A; FARIA, L.A; LIMA, M. J. C. O perfil dos raizeiros e a comercialização de plantas medicinais em feiras livres no município de Vitória da Conquita, Bahia. Ex@tasOnline. 2014;5(2):8-18. Disponível em: http://www2.uesb.br/exatasonline/images/V5N2pag818.pdf. acesso em: 30 set. 2016

TRAVENZOLI，N. M; MOREIRA， L. C. B. Plantas medicinais e ritualísticas vendidas em feiras livres cadastradas na região metropolitana do vale do aço. $10^{\mathrm{a}}$ Semana de Iniciação Científica e $1^{\text {a }}$ Semana de Extensão UnilesteMG "Iniciação Científica e Extensão: diferenciais acadêmicos."2009. 